\title{
Change in Plasma Renin Substrate Level after the Intravenous Furosemide Administration
}

\author{
Yoshihiro Kato, M.D., Masaharu Ikeda, * M.D., Teruo SaKaI, M.D., \\ and Kikuo Arakawa, M.D.
}

\begin{abstract}
SUMmaRY
Plasma renin substrate (PRS) was determined immediately before and $30 \mathrm{~min}$ after the intravenous administration of $40 \mathrm{mg}$ of furosemide in 26 hypertensive subjects. PRS level after the administration of furosemide was found elevated by $30.5 \pm 4.7 \%$ which was statistically sigficant.
\end{abstract}

\section{Additional Indexing Words :}

Angiotensin Hematocrit Plasma renin activity Sodium depletion

T $\mathrm{T}$ has been assumed that plasma renin substrate level is regulated by angiotensin II, ${ }^{1)}$ glucocorticoid, ${ }^{2 /}$ and estrogen ${ }^{3,4)}$ based upon static experiments. What may happen to the PRS level when it is rapidly consumed by an acute increase of renin secretion has not been investigated. By the use of furosemide, which is well known stimulator of renin secretion, ${ }^{5)-7)}$ acute change of PRS level is studied in the present report.

\section{Materials and Methods}

Twenty-six hypertensive subjects, 19 men and 7 women, with an average age of 41 , ranging from 13 to 70 , were studied either before starting any antihypertensive therapy or after discontinuing all medications for at least 1 week. They were kept on an ordinary hospital diet of 10-15 Gm of salt a day for 7 days. An initial blood sample for assay of plasma renin activity (PRA) and PRS was obtained in early morning without breakfast in recumbent position, being followed by the intravenous administration of $40 \mathrm{mg}$ of furosemide. The subjects were then kept standing for the next $60 \mathrm{~min}$, during which the second and third blood samples were taken at 30 th and 60 th min. PRA was measured by the method described

From the Second Department of Internal Medicine, Fukuoka University School of Medicine, 34 Nanakuma, Fukuoka 814, Japan.

* Present address: Clinical Research Institute of Montreal, Montreal, Quebec, Canada H2W 1R7.

Reprint requests to: Professor Kikuo Second Department of Internal Medicine, Fukuoka University School of Medicine, 34 Nanakuma, Fukuoka 814, Japan.

Received for publication September 21, 1978. 
by Arakawa et al, ${ }^{81}$ and PRS by its modification with an addition of excess human kidney renin which was prepared according to the procedure described by Arakawa et al, ${ }^{9}$

Statistical analysis was performed using Student's t test. Data are presented as the mean \pm the standard error of the mean (SEM), and $p$ value of less than 0.05 was considered significant.

\section{RESULTS}

The PRS levels before and after the administration of furosemide are compared in Fig. 1. The mean value of PRS level before the administration of furosemide was $999.6 \pm 69.2 \mathrm{ng} / \mathrm{ml}$, and, after furosemide, $1340 \pm 116.5$ $\mathrm{ng} / \mathrm{ml}$. The change was significant $(\mathrm{p}<0.001)$. Because of diuresis caused by furosemide, hematocrit increased from $43.5 \pm 3.0 \%$ to $46.3 \pm 3.0 \%$, which was also statistically significant $(p<0.02)$. However, as the rate of increased hematocrit value $(2.9 \pm 0.86 \%)$ was considerably less than that of increased PRS level $(30.5 \pm 4.7 \%)$, it is apparent that the elevation of PRS level was not merely due to the hemo-concentration.

The levels of PRA before and after the administration of furosemide are

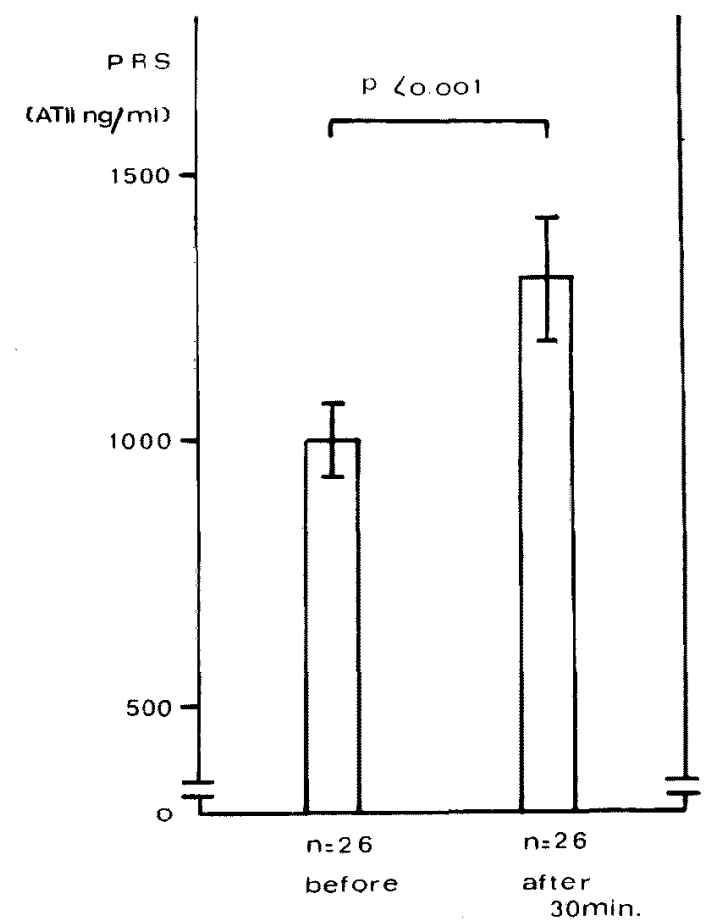

Fig. 1. Changes in the levels of plasma renin substrate before and after $40 \mathrm{mg}$ of furosemide. 


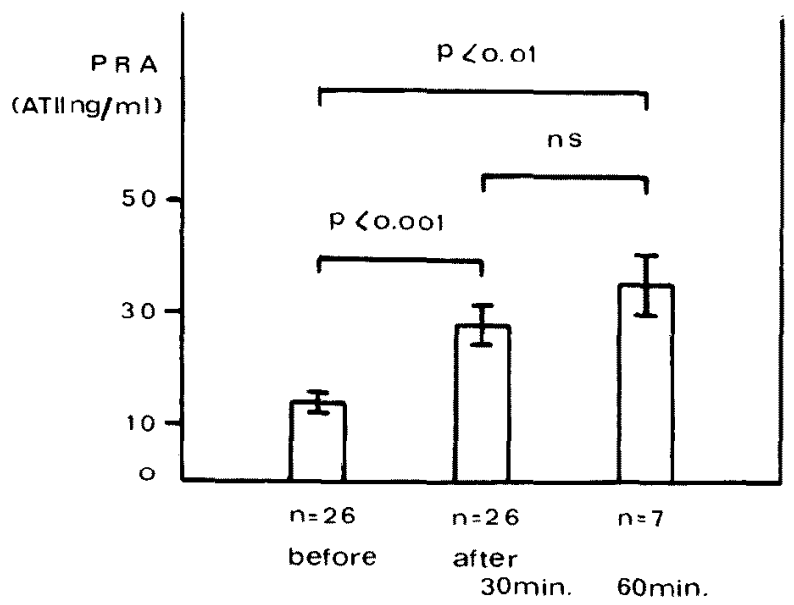

Fig. 2. Changes in the levels of plasma renin activity before and after $40 \mathrm{mg}$ of furosemide.

shown in Fig. 2. The mean value of PRA before the administration of furosemide was $13.8 \pm 1.9 \mathrm{ng} / \mathrm{ml}$ and increased to $27.3 \pm 4.4 \mathrm{ng} / \mathrm{ml}$ at 30 th min. The change was significant $(\mathrm{p}<0.001)$. PRA value $60 \mathrm{~min}$ after furosemide was $35.2 \pm 5.8 \mathrm{ng} / \mathrm{ml}(n=7)$ and this was also a significant change $(\mathrm{p}<0.01)$.

\section{Discussion}

An increased renin after the administration of furosemide should consume PRS, and consequently PRS should decrease. In contrast to the expectation, however, the present study disclosed that the PRS level did not decrease, but rather significantly increased after the administration of furosemide, along with the increase of PRA. In fact the increase of PRS level after furosemide far exceeded even the amount of what might be expected from hemoconcentration. Thus, present experiment has clearly shown that furosemide administration definitely resulted in a rapid increase of PRS, as well as that of PRA.

The mechanism of this rapid elevation of PRS level after furosemide is not investigated here. Several possibilities, like the followings, remain to be elucidated; a) either increased PRA itself or thereby increased angiotensin II, b) depletion of serum sodium, c) sympathicotonic reflex, both indirectly, or, d) furosemide itself, directly, may stimulate renin substrate secretion.

\section{ACKNoWLEDGments}

Technical assistance of Miss Takako Geji is acknowledged. This work was 
supported by Research Grant B-148195 from Japanese Ministry of Education, and, in part, by Japanese Heart Foundation.

\section{REFERENCES}

1. Nasjletti A, Masson GMC: Stimulation of angiotensinogen formation by renin and angiotensin. Proc Soc Exptl Med 142: 307, 1973

2. Hasegawa H, Nasjletti A, Rice K, Masson GMC: Role of pituitary and adrenals in the regulation of plasma angiotensinogen. Am J Physiol 225: 1, 1973

3. Helmer $\mathrm{OM}$, Judson WE: Influence of high renin substrate levels on renin-angiotensin system in pregnancy. Am J Obstet Gynecol 99: 9, 1967

4. Newton MA, Sealey JE, Ledingham JGG, Laragh JH: High blood pressure and oral contraceptives. Am J Obstet Gynecol 101: 1037, 1968

5. Brunner HR, Sealey JE, Laragh JH: Renin subgroups in essential hypertension. Circulat Res 32, 33 (suppl 1): 99, 1973

6. Fukuchi S, Nakajima K, Takenouchi T, Nishisato K: Plasma aldosterone in essential hypertension with low renin activity. Jap Girculat J 38: 1071, 1974

7. Kaplan NM, Ken DC, Holland OB, Kramer NJ, Higgins J, Gomez-Sanchez C: The intravenous furosemide test. A simple way to evaluate renin responsiveness. Ann Intern Med 84: 639,1976

8. Arakawa K, Minohara A, Yamada J, Uemura N, Nakamura M: Microdetermination of human plasma renin activity with the addition of homologous substrate. Clin Chim Acta 22: 309,1968

9. Arakawa K, Nakatani M, Minohara A, Nakamura M: Isolation and amino acid composition of human angiotensin 1. Biochem J 104: 900, 1967 